Internat. J. Math. \& Math. Sci.

Vol. 23, No. 8 (2000) 521-527

S0161171200003574

(C) Hindawi Publishing Corp.

\title{
ON CERTAIN SUFFICIENT CONDITIONS FOR STARLIKENESS
}

\section{NIKOLA TUNESKI}

(Received 22 October 1998 and in revised form 29 June 1999)

ABSTRACT. We consider certain properties of $f(z) f^{\prime \prime}(z) / f^{\prime 2}(z)$ as a sufficient condition for starlikeness.

Keywords and phrases. Univalent, starlike.

2000 Mathematics Subject Classification. Primary 30C45.

1. Introduction and preliminaries. Let $A$ denote the class of functions $f(z)$ which are analytic in the unit disc $U=\{z:|z|<1\}$ with $f(0)=f^{\prime}(0)-1=0$.

For a function $f(z) \in A$ we say that it is starlike in the unit disc $U$ if and only if

$$
\operatorname{Re}\left\{z \frac{f^{\prime}(z)}{f(z)}\right\}>0
$$

for all $z \in U$. We denote by $S^{*}$ the class of all such functions. We denote by $K$ the class of convex functions in the unit disc $U$, i.e., the class of univalent functions $f(z) \in A$ for which

$$
\operatorname{Re}\left\{1+z \frac{f^{\prime \prime}(z)}{f^{\prime}(z)}\right\}>0
$$

for all $z \in U$.

Both of the above mentioned classes are subclasses of univalent functions in $U$ and more $K \subset S^{*}([1,2])$.

Let $f(z)$ and $g(z)$ be analytic in the unit disc. Then we say that $f(z)$ is subordinate to $g(z)$, and we write $f(z) \prec g(z)$, if $g(z)$ is univalent in $U, f(0)=g(0)$ and $f(U) \subseteq g(U)$.

In this paper, we use the method of differential subordinations. The general theory of differential subordinations introduced by Miler and Mocanu is given in [5]. Namely, if $\phi: C^{2} \rightarrow C$ (where $C$ is the complex plane) is analytic in domain $D$, if $h(z)$ is univalent in $U$, and if $p(z)$ is analytic in $U$ with $\left(p(z), z p^{\prime}(z)\right) \in D$ when $z \in U$, then we say that $p(z)$ satisfies a first-order differential subordination if

$$
\phi\left(p(z), z p^{\prime}(z)\right) \prec h(z) .
$$

We say that the univalent function $q(z)$ is dominant of the differential subordination (1.3) if $p(z) \prec q(z)$ for all $p(z)$ satisfying (1.3). If $\tilde{q}(z)$ is a dominant of (1.3) and $\tilde{q}(z) \prec q(z)$ for all dominants of (1.3), then we say that $\tilde{q}(z)$ is the best dominant of the differential subordination (1.3).

In the following section, we need the following lemma of Miller and Mocanu [6]. 
LEMMA 1.1 [6]. Let $q(z)$ be univalent in the unit disc $U$, and let $\theta(\omega)$ and $\phi(\omega)$ be analytic in a domain $D$ containing $q(U)$, with $\phi(\omega) \neq 0$ when $\omega \in q(U)$. Set $Q(z)=$ $z q^{\prime}(z) \phi(q(z)), h(z)=\theta(q(z))+Q(z)$, and suppose that

(i) $Q(z)$ is starlike in the unit disc $U$,

(ii) $\operatorname{Re}\left\{z\left(h^{\prime}(z) / Q(z)\right)\right\}=\operatorname{Re}\left\{\theta^{\prime}(q(z)) / \phi(q(z))+z\left(Q^{\prime}(z) / Q(z)\right)\right\}>0, z \in U$.

If $p(z)$ is analytic in $U$, with $p(0)=q(0), p(U) \subseteq D$ and

$$
\theta(p(z))+z p^{\prime}(z) \phi(p(z)) \prec \theta(q(z))+z q^{\prime}(z) \phi(q(z))=h(z)
$$

then $p(z) \prec q(z)$, and $q(z)$ is the best dominant of (1.4).

Even more we need the following lemma, which in more general form is due to Hallenbeck and Ruscheweyh [3].

LEMMA 1.2 [3]. Let $G(z)$ be a convex univalent in $U, G(0)=1$. Let $F(z)$ be analytic in $U, F(0)=1$ and let $F(z) \prec G(z)$ in $U$. Then for all $n \in N_{0}$

$$
(n+1) z^{-n-1} \int_{0}^{z} t^{n} F(t) d t \prec(n+1) z^{-n-1} \int_{0}^{z} t^{n} G(t) d t .
$$

2. Main results and consequences. In this part, we use Lemmas 1.1 and 1.2 to obtain some conditions for $f(z) f^{\prime \prime}(z) / f^{\prime 2}(z)$ which lead to starlikeness.

THEOREM 2.1. If $f \in A$ and

$$
\frac{f(z) f^{\prime \prime}(z)}{f^{\prime 2}(z)} \prec 2-\frac{2}{(1-z)^{2}}=h(z)
$$

then $f \in S^{*}$.

Proof. We choose $p(z)=z\left(f^{\prime}(z) / f(z)\right) ; q(z)=(1-z) /(1+z) ; \phi(\omega)=1 / \omega^{2}$; $\theta(\omega)=1-(1 / \omega)$. Then $q(z)$ is univalent in $U ; \theta(\omega)$ and $\phi(\omega)$ are analytic with domain $D=\mathbf{C} \backslash\{0\}$ which contains $q(U)=\{z: \operatorname{Re}(z)>0\}$ and $\phi(\omega) \neq 0$ when $\omega \in$ $q(U)$. Further

$$
Q(z)=z q^{\prime}(z) \phi(q(z))=-\frac{2 z}{(1-z)^{2}}
$$

is starlike in $U$, and for the function

$$
h(z)=\theta(q(z))+Q(z)=\frac{2 z(z-2)}{(1-z)^{2}}=2-\frac{2}{(1-z)^{2}}
$$

we have

$$
\operatorname{Re}\left\{z \frac{h^{\prime}(z)}{Q(z)}\right\}=\operatorname{Re}\left\{\frac{2}{1-z}\right\}>0, \quad z \in U .
$$

Also, $p$ is analytic in $U, p(0)=q(0)=1$ and $p(U) \subset D$ because $0 \notin p(U)$. Therefore the conditions of Lemma 1.1 are satisfied and we obtain that if

$$
\theta(p(z))+z p^{\prime}(z) \phi(p(z))=\frac{f(z) f^{\prime \prime}(z)}{f^{\prime 2}(z)} \prec 2-\frac{2}{(1-z)^{2}}=h(z)
$$


then

$$
\frac{z f^{\prime}(z)}{f(z)}=p(z) \prec q(z)=\frac{1-z}{1+z}
$$

i.e., $f \in S^{*}$.

EXAMPLE 2.2. The function $f(z)=z-z^{2} / 2$ belongs to the class $A$ and $f(z) f^{\prime \prime}(z) /$ $f^{\prime 2}(z)=1 / 2-(1-z)^{2} / 2$ is subordinated to $2-2 /(1-z)^{2}$. So, from Theorem 2.1 $f \in S^{*}$. Obtaining starlikeness from $z f^{\prime}(z) / f(z)=(2-2 z) /(2-z)$ needs one step more.

COROLlary 2.3. Let $f \in A$.

(i) Let $D=\{z: \operatorname{Re} z<1.5\} \cup\left\{z: \operatorname{Re} z \geq 1.5,|\operatorname{Im} z|>\sqrt{-3+2 \operatorname{Re} z}\right.$. If $f(z) f^{\prime \prime}(z) /$ $f^{\prime 2}(z) \in D, z \in U$, then $f \in S^{*}$;

(ii) if $\operatorname{Re}\left\{f(z) f^{\prime \prime}(z) / f^{\prime 2}(z)\right\}<3 / 2, z \in U$, then $f \in S^{*}$;

(iii) if $\left|f(z) f^{\prime \prime}(z) / f^{\prime 2}(z)\right|<3 / 2, z \in U$, then $f \in S^{*}$.

Proof. (i) We have that $f(z) f^{\prime \prime}(z) / f^{\prime 2}(z)$ and $h(z)$ defined by (2.1) are analytic in $U ; f(0) f^{\prime \prime}(0) / f^{\prime 2}(0)=h(0)=0$ and $h(z)$ is univalent in $U$ (it is one to one mapping because only one of the points $1+\sqrt{2 /(2-\omega)}$ is in $U)$. So, we get that (2.1) is equivalent with

$$
\frac{f(z) f^{\prime \prime}(z)}{f^{\prime 2}(z)} \in h(U), \quad z \in U
$$

and it is enough to prove that $h(U)=D$. After some transformations we obtain

$$
\left|h\left(e^{i \theta}\right)-2\right|=\frac{1}{2 \sin ^{2} \theta / 2}, \quad \arg \left\{h\left(e^{i \theta}\right)-2\right\}=-\theta,
$$

i.e.,

$$
\operatorname{Re}\left\{h\left(e^{i \theta}\right)\right\}-2=\frac{1}{2}\left(\operatorname{ctg}^{2} \frac{\theta}{2}-1\right), \quad \operatorname{Im}\left\{h\left(e^{i \theta}\right)\right\}=-\operatorname{ctg} \frac{\theta}{2} .
$$

So

$$
\operatorname{Im}\left\{h\left(e^{i \theta}\right)\right\}= \pm \sqrt{-3+2 \operatorname{Re} h\left(e^{i \theta}\right)}
$$

and because of $h(0)=0<3 / 2$ we can say that $h(U)=D$. Parts (ii) and (iii) follow directly from (i).

EXAMPLE 2.4. The function $f(z)=1-e^{-z}$ is in $A$ and the real part of $f(z) f^{\prime \prime}(z) /$ $f^{\prime 2}(z)=1-e^{z}$ is smaller than $3 / 2$ for all $z \in U$. So $f(z)$ is starlike according to Corollary 2.3(ii). It have been more complicated to realize it from $z f^{\prime}(z) / f(z)=$ $z /\left(e^{z}-1\right)$.

Now, using Lemma 1.2 we prove a theorem which we used to improve the results from Corollary 2.3(ii) and (iii) and to obtain some other results.

THEOREM 2.5. Let $f \in A$. If $f(z) f^{\prime \prime}(z) / f^{\prime 2}(z) \prec h(z), h(0)=0$ and $h(z)$ is a convex univalent in $U$ then

$$
\frac{f(z)}{z f^{\prime}(z)} \prec 1-\frac{1}{z} \int_{0}^{z} h(t) d t
$$


Proof. Let $F(z)=\left(f(z) / f^{\prime}(z)\right)^{\prime}=1-f(z) f^{\prime \prime}(z) / f^{\prime 2}(z)$ and $G(z)=1-h(z)$, $z \in U$. Then $G(z)$ is a convex univalent in $U, G(0)=1 ; F(z)$ is analytic in $U, F(0)=1$. Further we have that

$$
1-\frac{f(z) f^{\prime \prime}(z)}{f^{\prime 2}(Z)}=F(z) \prec G(z)=1-h(z) .
$$

Therefore the conditions of Lemma 1.2 are satisfied and for $n=0$ we obtain

$$
\frac{1}{z} \int_{0}^{z} F(t) d t \prec \frac{1}{z} \int_{0}^{z} G(t) d t .
$$

If we apply the definitions of $F(z)$ and $G(z)$ in the result above and use the following fact which is true because $F(z)$ is analytic

$$
\int_{0}^{z}\left(\frac{f(t)}{f^{\prime}(t)}\right)^{\prime} d t=\frac{f(z)}{f^{\prime}(z)}-\frac{f(0)}{f^{\prime}(0)}=\frac{f(z)}{f^{\prime}(z)},
$$

we obtain that

$$
\frac{f(z)}{z f^{\prime}(z)} \prec \frac{1}{z} \int_{0}^{z}(1-h(t)) d t=1-\frac{1}{z} \int_{0}^{z} h(t) d t
$$

REMARK 2.6. If $h(z)$ is convex, from [4], $1-(1 / z) \int_{0}^{z} h(t) d t$ is also convex.

In the following corollaries, we deliver some interesting results using Theorem 2.5.

COROLlary 2.7. Let $f \in A$. If $\left|f(z) f^{\prime \prime}(z) / f^{\prime 2}(z)\right|<2$ then $f \in S^{*}$.

Proof. From $\left|f(z) f^{\prime \prime}(z) / f^{\prime 2}(z)\right|<2, z \in U$, because $h(z)=2 z$ is univalent and $f(0) f^{\prime \prime}(0) / f^{\prime 2}(0)=h(0)=0$ we get that

$$
\frac{f(z) f^{\prime \prime}(z)}{f^{\prime 2}(z)} \prec 2 z=h(z) .
$$

Further, $h(z)$ is convex, so the conditions from Theorem 2.5 are satisfied, and we obtain

$$
\frac{f(z)}{z f^{\prime}(z)} \prec 1-\frac{1}{z} \int_{0}^{z} h(t) d t=1-z
$$

i.e.,

$$
\operatorname{Re}\left\{\frac{f(z)}{z f^{\prime}(z)}\right\}>0
$$

Because of that $\operatorname{Re}\left\{z f^{\prime}(z) / f(z)\right\}>0$, i.e., $f \in S^{*}$.

REMARK 2.8. The result from Corollary 2.7 is the same as in [7] (Theorem 1, for $a=0$ and $b=-1$ ) and it is better than the result from Corollary 2.3(iii).

EXAMPLE 2.9. The same function as in Example 2.4, $f(z)=1-e^{-z}$, can be used to illustrate Corollary 2.7:

$$
\left|\frac{f(z) f^{\prime \prime}(z)}{f^{\prime 2}(z)}\right|=\left|1-e^{z}\right|<|1-e|<2, \quad z \in U,
$$

and $f(z)$ is starlike. 
COROllary 2.10. Let $f \in A$.

(i) If $f(z) f^{\prime \prime}(z) / f^{\prime 2}(z) \prec 2 \alpha z /(1+z)=h(z), 0<\alpha \leq 1 / 2(1-\ln 2)$, then $f \in S^{*}$.

(ii) If $\operatorname{Re}\left\{f(z) f^{\prime \prime}(z) / f^{\prime 2}(z)\right\}<1 / 2(1-\ln 2)=1.629445 \ldots, z \in U$, then $f \in S^{*}$.

Proof. (i) From $h(0)=0$ and $h(z)$ is a convex function in the unit disc $U$, by Theorem 2.5 we get that

$$
\frac{f(z)}{z f^{\prime}(z)} \prec 1-\frac{1}{z} \int_{0}^{z} h(t) d t=1-2 \alpha+2 \alpha \frac{\ln (1+z)}{z}=g(z) .
$$

Now, from

$$
\begin{aligned}
& \operatorname{Re}\{g(z)\}=1-2 \alpha+\frac{2 \alpha}{|z|^{2}}[x \ln |1+z|+y \arg (1+z)], \\
& \operatorname{Im}\{g(z)\}=\frac{2 \alpha}{|z|^{2}}[x \arg (1+z)-y \ln |1+z|],
\end{aligned}
$$

where $z=x+i y$, it follows that $g(U)$ is symmetric with respect to the $x$-axis. It is also convex (Remark 2.6) and so

$$
\operatorname{Re}\{g(z)\}>\min \{g(1), g(-1)\}=g(1)=1-2 \alpha+2 \alpha \ln 2>0, \quad z \in U .
$$

Thus, from $f(z) / z f^{\prime}(z) \prec g(z)$ we get that $\operatorname{Re}\left\{f(z) / z f^{\prime}(z)\right\}>0, z \in U$ and $\operatorname{Re}\left\{z\left(f^{\prime}(z) / f(z)\right)\right\}>0, z \in U$, i.e., $f \in S^{*}$.

(ii) $f(z) f^{\prime \prime}(z) / f^{\prime 2}(z)$ is analytic in the unit disc $U, h(z)$ is univalent in $U$ and $f(0) f^{\prime \prime}(0) / f^{\prime 2}(0)=h(0)=0$. Therefore the condition from (i)

$$
\frac{f(z) f^{\prime \prime}(z)}{f^{\prime 2}(z)} \prec \frac{2 \alpha z}{1+z}=h(z)
$$

is equivalent with

$$
\frac{f(z) f^{\prime \prime}(z)}{f^{\prime 2}(z)} \in h(U), \quad z \in U
$$

Now, from $\operatorname{Re}\left\{h\left(e^{i \theta}\right)\right\}=\alpha$ and $h(0)=0<\alpha$ we get that $h(z)$ maps the unit disc $U$ into the half plane with real part less than $\alpha$. So the condition from (i) is equivalent with

$$
\operatorname{Re}\left\{\frac{f(z) f^{\prime \prime}(z)}{f^{\prime 2}(z)}\right\}<\alpha, \quad z \in U
$$

If we put $\alpha=1 / 2(1-\ln 2)$ here, using (i) we obtain the statement of (ii).

REMARK 2.11. Because $1 / 2(1-\ln 2)=1.629445 \cdots>1.5$, the result from Corollary 2.10(ii) is better than the result from the Corollary 2.3(ii).

EXAMPLE 2.12. For $f(z)=\left(1-e^{-2 z}\right) / 2$ we have that $f \in A$ and $f(z) f^{\prime \prime}(z) / f^{\prime 2}(z)=$ $1-e^{2 z}$. Further for $z=e^{i \theta}$ we get

$$
\operatorname{Re}\left\{1-e^{2 z}\right\}=1-e^{2 \cos \theta} \cos (2 \sin \theta)
$$


with maximum value $1.603838 \ldots$ which it attains for $\theta=1.246054 \ldots$, i.e., for the solution of the equation

$$
\theta+2 \sin \theta=\pi
$$

So from Corollary 2.10(ii) we obtain that $f(z)$ is starlike. Starlikeness of $f(z)$ could not have been derived using Corollary 2.3. Also, because for $z=1$

$$
\left|\frac{f(z) f^{\prime \prime}(z)}{f^{\prime 2}(z)}\right|=\left|1-e^{2 z}\right|>2,
$$

we cannot use Corollary 2.7.

In the following corollary, we see what is happening if $f(z) f^{\prime \prime}(z) / f^{\prime 2}(z), z \in U$, is in the half plane right from $1 / 2(1-\ln 2)$.

COROLlary 2.13. Let $f \in A$.

(i) If $f(z) f^{\prime \prime}(z) / f^{\prime 2}(z) \prec-\ln (1+\alpha z)=h(z), 0<\alpha \leq 1$, then $f \in S^{*}$;

(ii) If $\operatorname{Re}\left\{f(z) f^{\prime \prime}(z) / f^{\prime 2}(z)\right\} \geq a>-\ln 2=-0.6931 \ldots$ and $\mid \operatorname{Im}\left\{f(z) f^{\prime \prime}(z) /\right.$ $\left.f^{\prime 2}(z)\right\} \mid<\arccos 1 /\left(2 e^{a}\right), z \in U$, then $f \in S^{*}$.

Proof. (i) $h(0)=0$ and $h(z)$ is a univalent function in the unit disc $U$ because $h(z)$ is analytic in $U$ and it is one to one mapping. From $\alpha \leq 1$ we get that

$$
\operatorname{Re}\left\{1+z \frac{h^{\prime \prime}(z)}{h^{\prime}(z)}\right\}=\operatorname{Re}\left\{\frac{1}{1+\alpha z}\right\}>0, \quad z \in U,
$$

i.e., $h(z)$ is a convex function in the unit disc $U$. Therefore from Theorem 2.5 we obtain

$$
\frac{f(z)}{z f^{\prime}(z)} \prec 1-\frac{1}{z} \int_{0}^{z} h(t) d t=\left(1+\frac{1}{\alpha z}\right) \ln (1+\alpha z)=g(z) .
$$

Now, $g(U)$ is symmetric with respect to the $x$-axis and $g(z)$ is a convex function (Remark 2.6). So for $z \in U$

$$
\begin{aligned}
\operatorname{Re}\{g(z)\} & >\min \{g(1), g(-1)\} \\
& =\min \left\{\left(1+\frac{1}{\alpha}\right) \ln (1+\alpha),\left(1-\frac{1}{\alpha}\right) \ln (1-\alpha)\right\} \geq 0
\end{aligned}
$$

and from $f(z) / z f^{\prime}(z) \prec g(z)$ we get that $\operatorname{Re}\left\{f(z) / z f^{\prime}(z)\right\}>0$, i.e., $\operatorname{Re}\left\{z f^{\prime}(z) / f(z)\right\}$ $>0, z \in U$, and $f \in S^{*}$.

(ii) $f(z) f^{\prime \prime}(z) / f^{\prime 2}(z)$ is analytic in the unit disc $U, h(z)$ is univalent in $U$ and $f(0) f^{\prime \prime}(0) / f^{\prime 2}(0)=h(0)=0$. Therefore the condition from (i), for $\alpha=1$

$$
\frac{f(z) f^{\prime \prime}(z)}{f^{\prime 2}(z)} \prec-\ln (1+z)=h_{1}(z)
$$

is equivalent to

$$
\frac{f(z) f^{\prime \prime}(z)}{f^{\prime 2}(z)} \in h_{1}(U), \quad z \in U .
$$

Further, $\operatorname{Re}\left\{h_{1}\left(e^{i \theta}\right)\right\}=-\ln 2 \cos (\theta / 2)$ and $\operatorname{Im}\left\{h_{1}\left(e^{i \theta}\right)\right\}=-\arg \left(1+e^{i \theta}\right)=-\theta / 2$. So, $\operatorname{Re}\left\{h_{1}\left(e^{i \theta}\right)\right\} \geq a$ for $|\theta| \geq 2 \arccos 1 /\left(2 e^{a}\right)$, and for such $\theta$ we get that $\left|\operatorname{Im}\left\{h_{1}\left(e^{i \theta}\right)\right\}\right|=$ $|\theta / 2| \geq \arccos 1 /\left(2 e^{a}\right)$. From here, because $h_{1}(0)=0>-\ln 2$ is on the same side of the curve $h_{1}\left(e^{i \theta}\right)$ with $a$, it follows that (2.32) is true, i.e., $f \in S^{*}$. 
EXAMPLE 2.14. The use of Corollary 2.13 can be illustrated with the function $f(z)=$ $\ln (1+z)$. It belongs to the class $A$ and $f(z) f^{\prime \prime}(z) / f^{\prime 2}(z)=-\ln (1+z)$, so from Corollary 2.13(i), for $a=1$, we get that $f \in S^{*}$. The starlikeness is not obvious from $z f^{\prime}(z) / f(z)=z /((1+z) \ln (1+z))$.

\section{REFERENCES}

[1] A. W. Goodman, Univalent Functions. Vol. I, Mariner Publishing Co. Inc., Tampa, Florida, 1983. MR 85j:30035a.

[2] _ Univalent Functions. Vol. II, Mariner Publishing Co. Inc., Tampa, Florida, 1983. MR 85j:30035b.

[3] D. J. Hallenbeck and S. Ruscheweyh, Subordination by convex functions, Proc. Amer. Math. Soc. 52 (1975), 191-195. MR 51\#10603. Zbl 311.30010.

[4] R. J. Libera, Some classes of regular univalent functions, Proc. Amer. Math. Soc. 16 (1965), 755-758. MR 31\#2389. Zbl 158.07702.

[5] S. S. Miller and P. T. Mocanu, Differential subordinations and univalent functions, Michigan Math. J. 28 (1981), no. 2, 157-172. MR 83c:30017. Zbl 456.30022.

[6] _ On some classes of first-order differential subordinations, Michigan Math. J. 32 (1985), no. 2, 185-195. MR 86h:30046. Zbl 575.30019.

[7] M. Obradović and S. Owa, On certain properties for some classes of starlike functions, J. Math. Anal. Appl. 145 (1990), no. 2, 357-364. MR 91d:30015. Zbl 707.30009.

TUNESKI: DePARTMENT OF MATHEMATICS AND COMPUTER SCIENCES, FACUlTY OF MECHANICAL ENGINEERING, UNIVERSITY OF "SV. KIRIL I METODIJ", KARPOS II B.B. 91000 SKOPJE, MACEDONIA E-mail address: niko1at@ereb.mf.ukim.edu.mk 


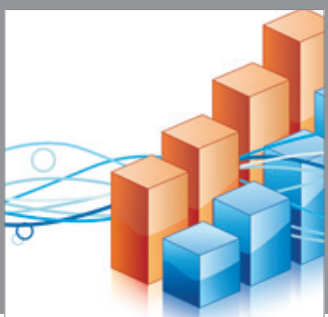

Advances in

Operations Research

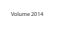

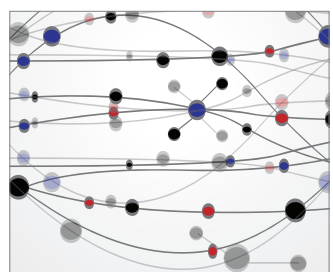

\section{The Scientific} World Journal
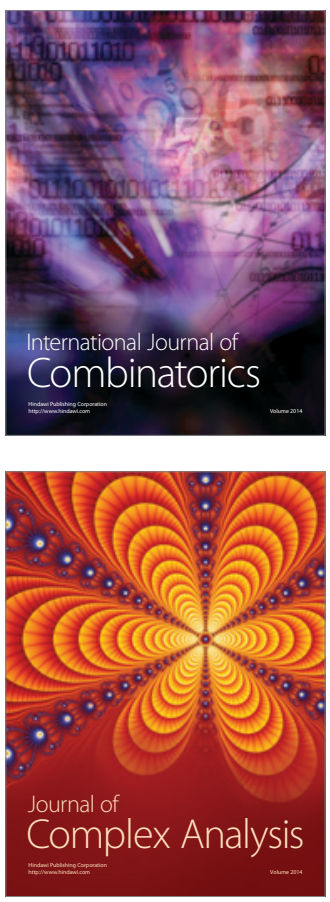

International Journal of

Mathematics and

Mathematical

Sciences
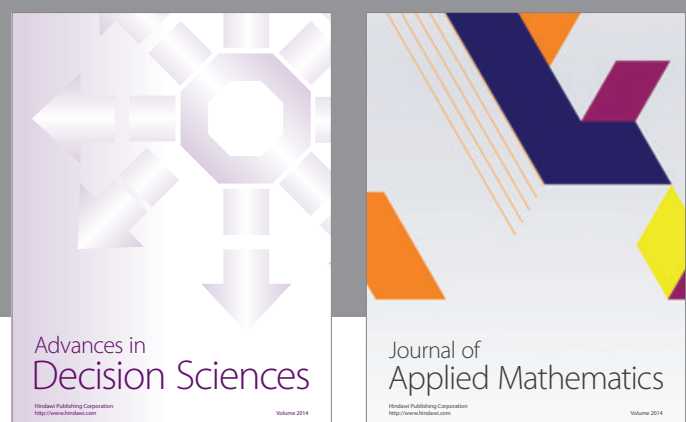

Journal of

Applied Mathematics
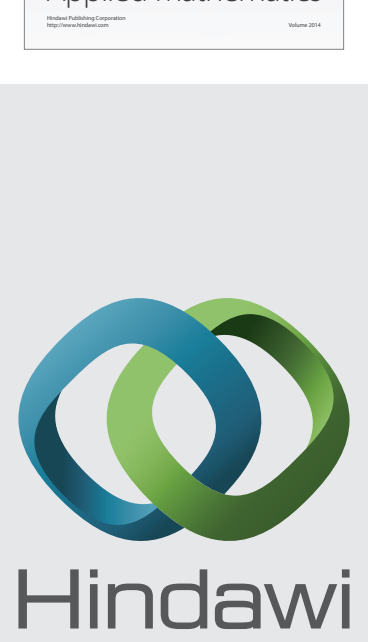

Submit your manuscripts at http://www.hindawi.com
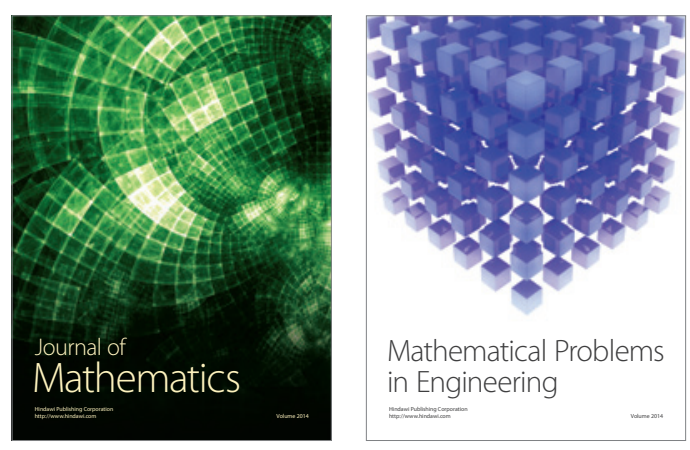

Mathematical Problems in Engineering
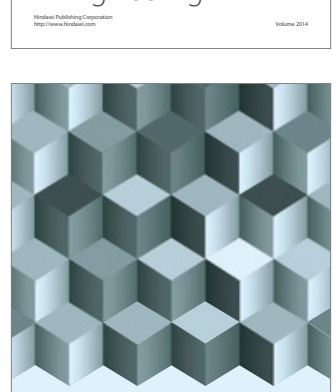

Journal of

Function Spaces
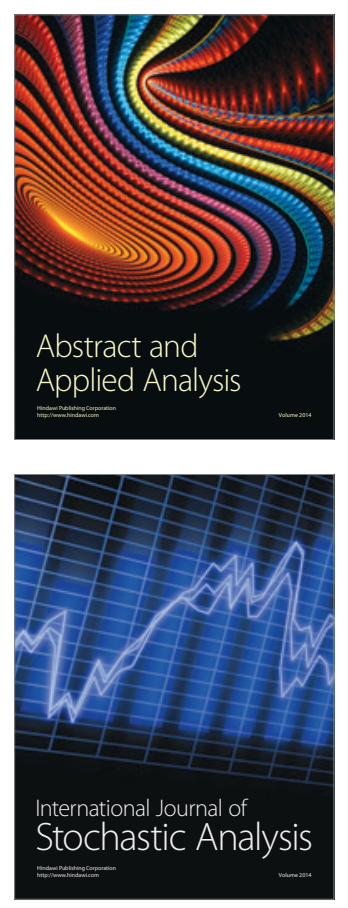

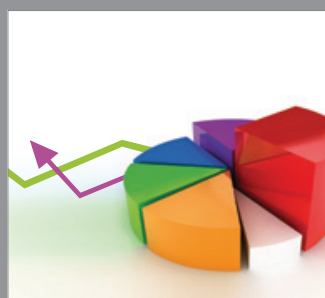

ournal of

Probability and Statistics

Promensencen
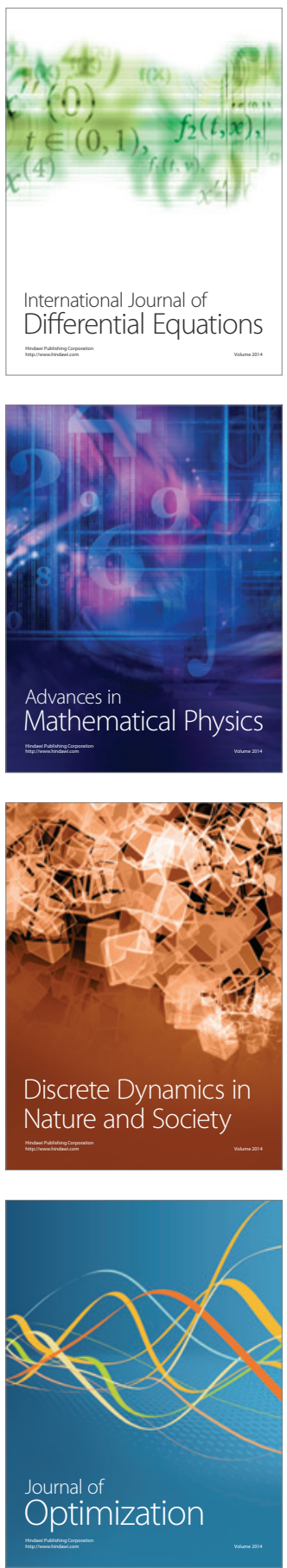